neo-Inositol was synthesized by Angyal and Matheson ${ }^{3}$ in 1955, but has not hitherto been found in Nature.

The phosphorylated neo-inositol was traced to an eluate fraction ('component $V^{\prime}$ )' from an ion-exchange column separation of soil phytin which also contained lower phosphates of myo-, scyllo- and DL-inositol. neo-Inositol was isolated from hydrolysates of this fraction by thin layer chromatography ${ }^{4}$ of the mixed hexa-acetates. After purification by fractional crystallization the neo-inositol hexaacetate crystallized as colourless prisms, m.p. $251^{\circ}-253^{\circ}$, from methanol. The identity of this product with authentic neo-inositol hexp-acetate ${ }^{3}$, m.p. $253^{\circ}$, was verified by a mixed melting point $\left(251^{\circ}-253^{\circ}\right)$ determination and comparison of infra-red spectra. The behaviour of the free inositol on paper chromatograms was similar to that of neo-inositol.

A sample of neo-inositol hexaphosphate was prepared by the method used by Posternak ${ }^{5}$ for the synthesis of phytic acid from myo-inositol. The product was examined by ion-exchange chromatography ${ }^{1}$ and shown to be a mixture of several neo-inositol phosphate esters. The final component eluted was the main constituent and its position corresponded to that of 'component $V$ ', the main neoinositol phosphate present in soil phytin. It is, therefore, concluded that the neo-inositol in the latter is present mainly as its hexaphosphate.

The origin of these isomers of phytic acid is unknown.

We thank Prof. S. J. Angyal for authentic samples and advice.

D. J. Cosgrove

Commonwealth Scientific and Industrial

Research Organization,

Division of Plant Industry, Canberra.

School of Chemistry,

University of New South Wales, Sydney.

' Cosgrove, D. J., Nature, 194, 1265 (1962).

${ }^{2}$ Angyal, S. J., and Krzeminski, Z. S., J. Chem. Soc., 3251 (1962)

Angyal, S. J., and Matheson, N. K., J. Amer. Chem. Soc., 77, 4343 (1955).

- Tate, M. E., and Bishop, C. T., Canad. J. Chem., 40, 1043 (1962).

s Posternak, S., Helv. Chim. Acta, 4, 158 (1921).

\section{Structure of Carboxyl Groups in Humic
Acids}

Schwartz and Asfeld ${ }^{1}$ have recently reported that four moles of water were evolved to one mole of carbon dioxide when humic acids, obtained from lignite, were decarboxylated at $150^{\circ}$ in a stream of dry nitrogen. Consequently, they suggested that the carboxyl functions of these acids were in the ionized form, - $-\mathrm{COO}-\mathrm{H}_{3} \mathrm{O}^{+\cdot} \cdot 3 \mathrm{H}_{2} \mathrm{O}$, although they were aware that this structure was contrary to that expected for relatively weak carboxylic acids. Since carboxyl groups, carboxylate ions, and hydrated hydronium ions all have characteristic absorption bands in the infra-red, it was possible for us to check the validity of the proposed structure. A sample of lignite was, therefore, obtained from the same source (North Dakota lignite of the Leonardite variety, marketed as 'Carbonox' by the Baroid Division, National Lead Co., Houston, Texas), and humic acids were prepared and decarboxylated by the procedures of the above authors. The infra-red spectra of potassium bromide pellets of the above materials (Fig. 1) were then recorded on a PerkinElmer 237 grating spectrophotometer.

The vibrational spectrum of the hydrated $\mathrm{H}_{3} \mathrm{O}^{+}$ion ${ }^{2}$ includes characteristic strong infra-red bands at 2,900 , 1,750 and 1,205 $\mathrm{cm}^{-1}$. Appreciable quantities of $\mathrm{H}_{3} \mathrm{O}^{+}$ ions cannot be present in the lignite or humic acids since the band at $1,750 \mathrm{~cm}^{-1}$ is absent from their spectra. Furthermore, since none of these materials shows strong absorption near 1,550 and $1,400 \mathrm{~cm}^{-1}$ they do not contain

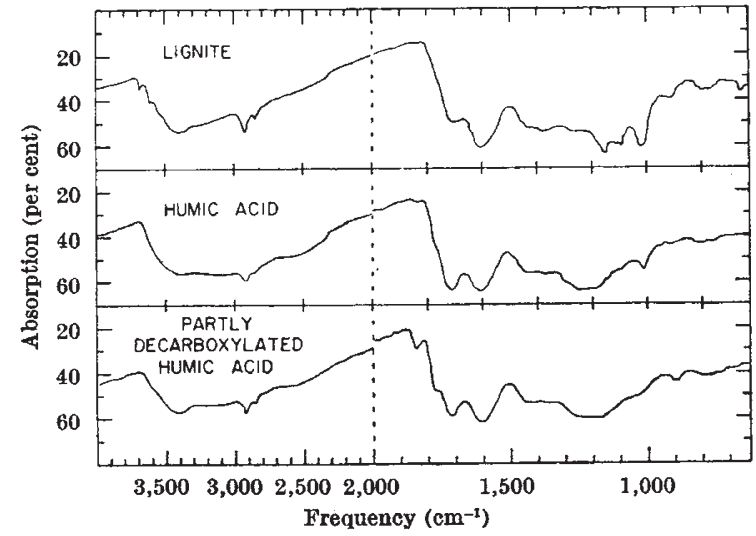

Fig. 1. Infra-red spectra of lignite, humic acids, and of humic acids atmosphere

carboxylate ions ${ }^{3}$. On the other hand, the strong absorp. tion bands characteristic of non-ionized carboxyl groups are present in the three spectra at $2,600 \mathrm{~cm}^{-1}$ (very broad), $1,712 \mathrm{~cm}^{-1}$, and $1,225 \mathrm{~cm}^{-1}$. As expected, the ratio of the intensities of these bands to other bands in each spectrum is greatest in the case of the humic acids. A broad band centered near $3,000 \mathrm{~cm}^{-1}$ also has a higher relative intensity in the spectrum of humic acids, and may be due to water molecules held to the carboxyl groups by moderately strong hydrogen bonds. It is of interest to note the appearance of weak bands at 1,843 and $1,768 \mathrm{~cm}^{-1}$ in the spectrum of the partially decarboxylated humic acids. These bands are probably due to small amounts of acid anhydrides formed by condensation between neighbouring carboxyl groups ${ }^{4}$.

On the basis of the infra-red evidence we conclude that the carboxyl groups in humic acids are mainly in the nonionic form. This conclusion is probably valid for all humic acids, since materials such as weathered sub-bituminous coal, Sphagnum peat and podzol soil yield humic acids the infra-red spectra ${ }^{4-6}$ of which are similar to the spectrum of humic acids shown here.

Mrchael FaLk

DONALD G. SMITH

Atlantic Regional Laboratory,

National Research Council, Halifax, Nova Scotia.

1 Schwartz, D., and Asfeld, L., Nature, 197, 177 (1963).

Falk, M., and Giguère, P. A., Canad. J. Chem., 35, 1195 (1957).

${ }^{3}$ Bellamy, L. J., The Infrared Spectra of Complex Molecules, second ed., 162 (Methuen and Co., London, 1958).

- Wood, J. C., Moschopedis, S. E., and den Hertog, W., Fuel, 40, 491 (1961).

${ }^{5}$ Smith, D. G., and Lorimer, J. W., Canad. J. Soil Sci. (in the press).

- Barton, D. H. R., and Schnitzer, M., Nature, 198, 217 (1963).

IN a recent communication ${ }^{1}$ we reported that four moles of water were evolved to one mole of carbon dioxide when humic acids, derived from a North Dakota lignite, were decarboxylated at $150^{\circ}$ in a stream of dry nitrogen. It was suggested that some of the acid function of the humic acids was in the ionized form, $-\mathrm{COO}-\mathrm{H}_{3} \mathrm{O}^{+} \cdot 3 \mathrm{H}_{2} \mathrm{O}$, although it was noted that relatively weak solid acids were not expected to be readily ionized. At the time the original experiments were carried out, infra-red spectra of potassium bromide pellets of the resultant humic acids which had been dehydrated and decarboxylated at $150^{\circ}$ for $65 \mathrm{~h}$ were recorded on a Beckman $I R-5$ spectrophotometer. It is the purpose of this communication to compare the original spectra with those reported in the preceding communication by Falk and Smith.

The spectra show strong absorption bands at 2,900 and $1,205 \mathrm{~cm}^{-1}$ and also show a shoulder at $1,750 \mathrm{~cm}^{-1}$. Based on previous work by Falk and Giguère ${ }^{2}$, the presence of these bands may be indicative of the hydrated $\mathrm{H}_{3} \mathrm{O}^{+}$ion. 